\title{
Independent Lung Ventilation for Reexpansion Pulmonary Edema*
}

\author{
Sheetal Garg ${ }^{1}$, Harinder Singh Bedi ${ }^{2 \#}$, Melchisedec Singh ${ }^{1}$, Valsa Abraham ${ }^{3}$ \\ ${ }^{1}$ Department of Cardiac Anesthesia, Christian Medical College \& Hospital, Ludhiana, India \\ ${ }^{2}$ Department of Cardio Vascular \& Thoracic Surgery, Christian Medical College \& Hospital, Ludhiana, India \\ ${ }^{3}$ Department of Anesthesia, Christian Medical College \& Hospital, Ludhiana, India \\ Email: "drhsbedicmc@gmail.com, "drhsbedi12@yahoo.com, "harinder.bedi@cmcludhiana.in
}

Received July 29, 2013; revised August 26, 2013; accepted September 2, 2013

Copyright (c) 2013 Sheetal Garg et al. This is an open access article distributed under the Creative Commons Attribution License, which permits unrestricted use, distribution, and reproduction in any medium, provided the original work is properly cited.

\begin{abstract}
Reexpansion pulmonary oedema (RPE) is a rare but potentially fatal complication with no clear cut guidelines for its management. When the injury to the lung is primarily one sided, conventional modes of ventilation can be ineffective and at times harmful. Selective or independent lung ventilation (ILV) is one of the therapeutic modality that can be used for the treatment of such cases. We report the successful treatment of reexpansion pulmonary oedema in 19-year-old boy using independent lung ventilation.
\end{abstract}

Keywords: Reexpansion Pulmonary Edema; Independent Lung Ventilation

\section{Introduction}

Unilateral reexpansion pulmonary oedema (RPE) is a rare but potentially fatal complication with no clear cut guidelines for its management. We report successful management of such a case with independent lung ventilation (ILV).

\section{Case Report}

A 19-year-old, 52-kg boy was presented in the emergency department after a road traffic accident with dyspnea. On examination there was decreased air entry on the right side. A chest radiograph revealed a hemopneumothorax of the right side. A chest tube was inserted on the right side with drainageof air and $500 \mathrm{ml}$ of collected blood. Standard negative pressure $(10 \mathrm{~cm}$ water) was applied through a two bottle system.

After 48 hours the patient became hemodynamically unstable. There was a sudden gush of blood through the chest tube and the drainage bottle had a collection of 800 $\mathrm{ml}$ of fresh blood. The patient was taken up for an emergency thoracotomy.

The patient was induced with standard anaesthetic drugs and the trachea intubated with a $37 \mathrm{~F}$ left sided

\footnotetext{
*There are no previous publications or presentations of this article. There is no source of funding. There are no conflicts of interest. \#Corresponding author.
}

Robertshaw double lumen tube (DLT). After checking the correct placement of the DLT with a bronchoscope the patient was positioned in the right lateral decubitus position. Right thoracotomy was performed, single lung ventilation was instituted with attempted collapse of right lung after the right pleura was opened. It was noted that the right lung would not collapse (Figure 1). There was pink frothy fluid flowing out through the right sided lumen of the DLT (Figure 2). A suction catheter was put on the affected side and suction was done while ventilating the left lung with $100 \%$ oxygen. A total transection-

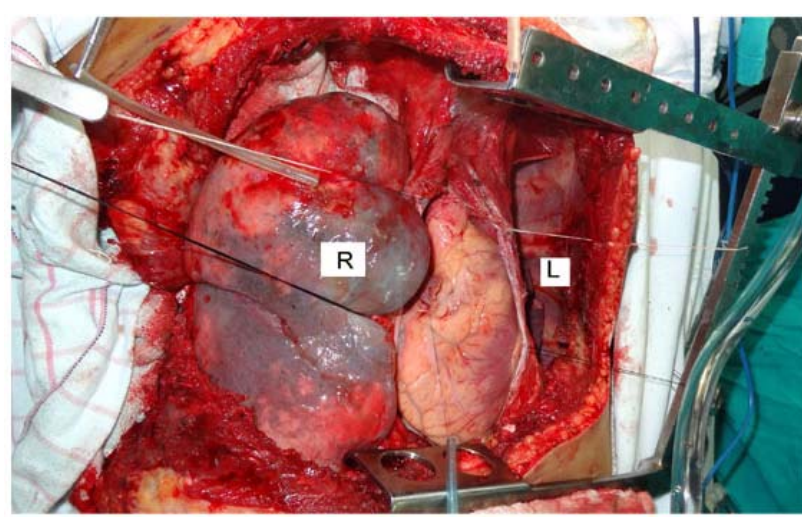

Figure 1. Operative photograph showing the non collapsing right lung (R), the left lung (L) which was easily collapsed on stopping its ventilation. 


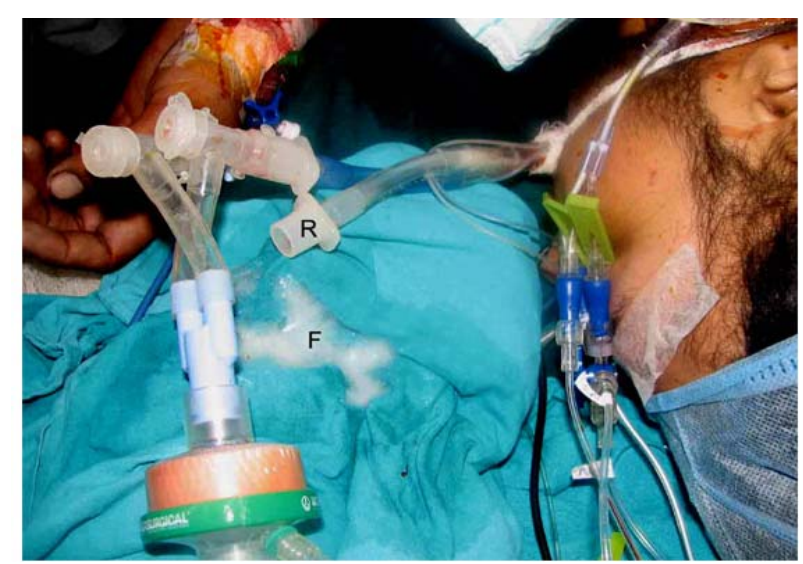

Figure 2. Frothy secretions (F) coming out of the right side (R) of the double lumen tube.

was found of the right subclavian artery. This had apparently clotted off initially and reopened some time after the insertion of the chest tube. As the right lung was just not deflating and was tamponading the cardiac function and to get adequate exposure the incision had to be converted to a bilateral thoracotomy (clamshell incision) and pericardiotomy (to rule out tamponade). The torn subclavian artery was repaired with a $8 \mathrm{~mm}$ ringed Gore tex interposition graft. On institution of two lung ventilation, the airway pressures were found to be high and pink frothy fluid continued pouring out through the right sided lumen of the DLT. The patient was shifted to the recovery room and the arterial blood gas analysis showed hypercarbia and hypoxemia at a $\mathrm{FiO}_{2}$ of $100 \%$. The airway pressures remained high and precluded adequate ventilation. Inspite of trying pressure control mode with high frequency thehypercarbia and hypoxemia persisted. Bemcause of the worsening pulmonary oedema, the inability to ventilate the right lung, ILV was instituted wherein two ventilators of the same make (MAQUET Servo s) were connected to the patient (Figure 3). The ventilator connected to the right lung was kept at pressure control(PC) mode with a pressure control above PEEP of 30 $\mathrm{cm}$ of $\mathrm{H}_{2} \mathrm{O}$, respiratory rate of 16 , PEEP of $8 \mathrm{~cm}$ of $\mathrm{H}_{2} \mathrm{O}$, oxygen concentration of $100 \%$, I:E ratio of 1:2. The ventilator connected to the left lung was kept on pressure regulated volume control mode (PRVC) mode with a tidal volume of $300 \mathrm{ml}(6 \mathrm{ml} / \mathrm{kg})$, respiratory rate of 16 , PEEP of $4 \mathrm{~cm}$ of $\mathrm{H}_{2} \mathrm{O}$, oxygen concentration of $60 \%$, I:E ratio of 1:2. Synchronization of the ventilators was not done. The patient was kept fully paralysed and sedated. Chest radiograph done in the recovery room showed resolving right pulmonary oedema (Figure 4). The pressure control above PEEP of the ventilator connected to the right lung was gradually decreased with increasing compliance of the right lung so as to deliver a tidal volume of $300 \mathrm{ml}$ and the $\mathrm{Fio}_{2}$ and PEEP were also gradually decreased with improving arterial blood gases over

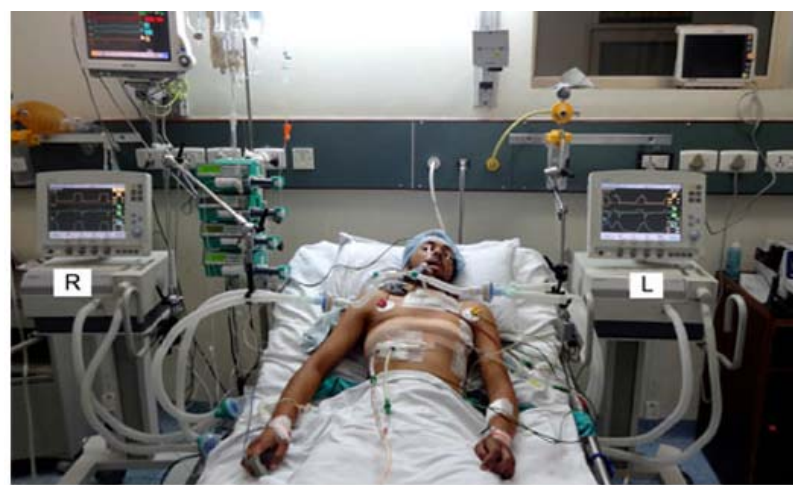

Figure 3. The two ventilators-left $(L)$ and right $(R)$ ventilating each side separately.

the next 48 hrs. The patient was ventilated for 48 hrs using ILV. With improving condition of the right lung as seen on the chest roentgenogram, minimal amount of bronchial secretions and a normal arterial blood gas with normalising ventilator settings of the right lung the DLT was changed to a single lumen tube and conventional ventilation instituted. After 24 hrs of conventional ventilation the patient was weaned off and extubated. The patient was discharged seven days after the surgery.

\section{Discussion}

Acute RPE is an unusual problem with devastating clinical consequences with an overall mortality of about $22 \%$ [1]. RPE is typically seen in lung collapsed for prolonged periods mainly by pneumothorax or pleural effusion. It is generally unlikely to occur if the duration of collapse is less than 3 days [2]. In this case the pulmonary oedema developed in the right lung immediately after reexpansion with copious amount of fluid being drained from the tracheal lumen of the DLT. The RPE is presumably due to increased fragility of the pulmonary capillaries, destruction of the capillaries due to reexpansion, increased capillary permeability due to capillary alveolar pressure gradient, decreased surfactant activity and abnormalities in the lymphatic drainage [3,4]. In cases where the disease or injury to the lung is primarily one sided and conventional mode of ventilation using a single lumen tube is ineffective, institution of ILV using a DLT wherein two ventilators are independently connected to the DLT and the lungs are ventilated as separate units. The ventilation can be done synchronously or asynchronously with equal safety and outcome [5-7]. In our case as the left sided DLT was already in place so we connected the two ventilators separately to the two lumens of the DLT and ventilated them using the same respiratory rate, I:E ratio and the trigger sensitivity so as to minimize the asynchrony but the mode of ventilation, tidal volume, $\mathrm{FiO}_{2}$ and PEEP were different.

ILV is one of the strategies recommended for man- 


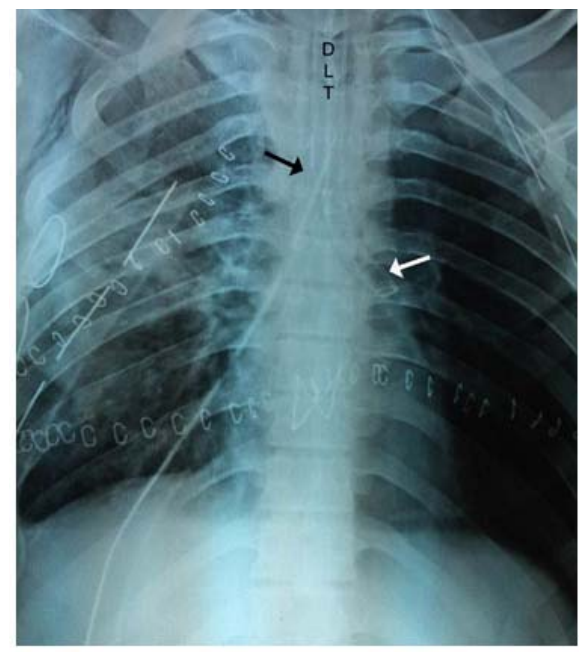

Figure 4. Postoperative chest $\mathrm{X}$-ray showing the double lumen tube (DLT), the left side (white arrow) and the right side (black arrow) of the DLT and right sided resolving pulmonary oedema.

agement of severe unilateral pulmonary disease [8]. No controlled clinical trials of ILV exist and there are no clear cut indications for its use. But application of ILV has shown to significantly improve oxygenation, recruit collapsed alveoli, limit peak inspiratory pressures, reduce hypoventilation and reduce the intrapulmonary shunt fraction. It also helps in preventing barotrauma to the normal lung, trickling of secretions from the deceased lung to the normal lung, application of therapeutic manoeuvres to the diseased lung like the application of high peep and adequate suctioning and lavage of the affected lung.

In our case we were able to correct the underlying pathophysiological process in 48 hrs by independent lung ventilation and the patient was extubated on the third day and recovered fully to be sent home on the seventh day of surgery.

\section{REFERENCES}

[1] S. Mahfood, W. R. Hix, B. L. Aaron, et al., "Reexpansion Pulmonary Edema," The Annals of Thoracic Surgery, Vol. 45, No. 3, 1988, pp. 340-345. doi:10.1016/S0003-4975(10)62480-0

[2] Y. Sohara, "Reexpansion Pulmonary Edema," Annals of Thoracic and Cardiovascular Surgery, Vol. 14, No. 4, 2008, pp. 205-209.

[3] Y. Sohara, "Reexpansion Pulmonary Edema-Basic and Clinic,” Japanese Journal of Clinical Physiology, Vol. 32, No. 2, 2000, pp. 105-110.

[4] R. W. Sewell, J. G. Fewel, F. L. Grover, et al., "Experimental Evaluation of Reexpansion Pulmonary Edema," The Annals of Thoracic Surgery, Vol. 26, No. 2, 1978, pp. 126-132. doi:10.1016/S0003-4975(10)63654-5

[5] K. M. Hillman and J. D. Barber, "Asynchronous Independent Lung Ventilation (AILV),” Critical Care Medicine, Vol. 8, No. 7, 1980, pp. 390-395. doi:10.1016/S0003-4975(10)63654-5

[6] D. Ost and T. Corbridge, "Independent Lung Ventilation,” Clinics In Chest Medicine, Vol. 17, No. 3, 1996, pp. 591-601. doi:10.1016/S0003-4975(10)63654-5

[7] D. Anatham, R. Jagadesan and P. E. C. Tiew, "Clinical Review: Independent Lung Ventilation in Critical Care,” Critical Care, Vol. 9, No. 6, 2005, pp. 594-600. doi:10.1186/cc3827

[8] T. J. Gallagher, M. J. Banner and R. A. Smith, "A Simplified Method of Independent Lung Ventilation," Critical Care Medicine, Vol. 8, No. 7, 1980, pp. 396-399. doi:10.1097/00003246-198007000-00007 